\title{
AUTOPOIETIC TURNS OF VALUE CO-CREATION IN MARKETING SYSTEMS: MEANING(S) OF FUEL- EFFICIENCY FOR HYBRID CAR USERS
}

Djavlonbek Kadirov, The University of Waikato

Richard Varey, The University of Waikato

\begin{abstract}
The authors investigate hybrid-car-user experiences to understand and conceptualise dynamics of autopoietically co-constructed marketing systems. The method is a fusion of grounded theory analysis, systems analysis, and the interpretive-constructionist tradition. The study finds that communications within the marketing system are directed toward creating only those conditions which would enable similar communications. The empathic understanding of the nature of autopoietic turns may shed some light to the process, which we call the value drift. The core value, that is sustainable mobility, which has rhetorically been offered by car manufacturers to be passively adopted in the marketing system, appears to be significantly altered (coconstructed) in a self-referential way.
\end{abstract}

\section{BACKGROUND}

Marketing has long been viewed as an integral part of the social systems of interactions (Alderson 1965; Bartels 1970; Dixon and Wilkinson 1982; Dowling 1983; Fisk 1967; Lazer 1971; Reidenbach and Oliva 1981; Sheth, Gardner, and Garrett 1988; Varey 2002). A large number of early contributors to marketing thought, such as Clark, Stewart, Dewhust, Duddy, Revzan, Vaile, and Alderson, saw marketing as social patterns of market actors' behavior (Sheth et al. 1988). Kuhn (1963, vii) described the marketing process "as one of several techniques of achieving consensus valuations in a society". The system perspective centres on the essential idea that marketing is (or should be seen as) a generator of social well-being and positive social consequences in the knowledge-based society (Fisk 1981). Though systems research themes and foci varied substantially from author to author, the main premise was that marketing is the co-constructed and emergent patterns of actions and interactions, and it cannot be attributed exclusively to any of the process participants. This view de-emphasises the importance of clear-cut delineation of roles between producers and consumers, connecting the systems view to the field of consumer research, particularly, the consumer emancipation research (Firat and Venkatesh 1995; Holt 2002; Kozinets 2002a). Especially, socially reflexive, recursive consumer actions are the cause of much interest in the field (Holstein and Gubrium, 2005).

The purpose of this work is to build an empiricallygrounded theory of marketing system dynamism. The place and role of citisens as marketplace participants in the system of marketing communications will specifically be investigated. Central to our investigation is the concept of autopoietic turns and its implication on meaning/value co- creation in the specific context of the hybrid-car-marketingsystem. Our key guiding research questions are: a) what is the essence of the marketing system when it is seen as a system of meaning/value communication?; b) how do citisens as consumers (and marketers) co-create and negotiate consumption meanings/value?; c) are original, and somewhat idealistic meanings (in our case the notion of sustainable mobility), suggested by marketers, in themselves sustainable?

\section{SYSTEMS PERSPECTIVE}

The primary source of systems thinking is the seminal work of Ludvig von Bertalanffy on the theory of general systems, which posits that scientific investigation should be directed toward a phenomenon in its wholeness, unity and organisation (i.e. it should be studied as a system). Von Bertalanffy (1950) argued that problems will lose relevance if concepts and relationships were studied in isolation, or through the process of synthesis of the "laws of disorder", whereas the real life problems appear to be those of "organisation". He considered the perspective to be radically different to the analysis of isolated fractions of phenomena. Luhmann (1995) described this change of emphasis as a paradigm shift in a Kuhnian sense. He suggests that the main transformation is about shifting attention from the dialectic of "parts versus whole" to that of "systems versus environment". This change becomes a useful approach to analyse the problem of the enlightenment of a human being, as it is problematic to conceptualise how a part, a human being, would accommodate the concerns of a whole, human society. In this, one is indispensably reminded of the rhetoric of the tragedy of commons (Shultz II and Holbrook 1999). Thus the social systems view cuts through the problem from a totally different perspective, focusing not on individuals, but on the unity of difference and the potentiality of communicative actions within the relevant environment. The emphasis is on perturbations of the systemic unity, which cannot be reduced to cause-effect relationships, but represents the wholeness of complex and chaotic interactions. The unity of difference and potentiality is a phenomenological term, which assumes that a system employs meanings, which acquire difference vis-à-vis its background, and dynamically interact with the world of its potential interpretations. For Luhmann (1995) the social system is the system of communication. Communication is considered as a unity of information, utterance and understanding. Note that communication here is understood in a broader sense than the way it is narrowly depicted in the conventional management literature (Varey 2000). It is rather seen as comprising all social action, interaction and 
change (Varey 2002). Marketing systems can be viewed as a special type of social systems. They are the systems of communications that constitute a marketplace. Autopoiesis refers to the "networks of productions of components that recursively, through their interactions, generate and realise the network that produces them and constitute, in the space in which they exist, the boundaries of the network as components that participate in the realization of the network." (Maturana 1981, 21). The autopoietic system reproduces and maintains itself independently. On this basis, Luhmann $(1995,9)$ developed the theory of selfreferential systems, which states that systems employ and build upon system-environment differences to create selfdescriptions. The existence of the environment with all its complexity is a necessary prerequisite for the creation of difference through reduction of complexity. The borders of the social systems are differences in communication and are created through the development of meanings. Meanings are self-referential adaptation to the complexity of the environment (Luhmann 1995). The process of discursive dissemination and circulation of system-unique meanings is termed a self-referential closure or an autopoietic turn.

\section{Interaction Artefacts}

\section{RESEARCH METHOD}

Our method of investigation of the issue of autopoietic turns in marketing systems is based on the principle of "observing the observer". The "observer" is a self-referential marketing system that develops selfdifferentiation within its environment. The idea is to look for "genuine interaction artefacts". This requires looking for any traces of market interaction left in information-carrying media, and they seem to be mostly accessible in published media and internet resources. This is like the looking for fossils by evolution anthropologists. The systemic interaction "fossils", which we use to reconstruct the social, may have become crystallised in debates and discussions stored in media through the use of language, which is considered as the main medium for conveying meanings (Luhmann 1995). Our intention is to avoid creating obtrusive, self-serving artificial autopoietic turns through the use of traditional interviewing techniques (Catterall, Maclaran, and Stevens 1996). In contrast, online forums, chatrooms, and weblogs seem to be more natural, unobtrusive and free-flowing. They perhaps are real (interactive, responsive, unbiased, free of time and peer pressure) indicators of what is happening in the marketing system (Yadav and Varadarajan 2005). "Netnography" is being increasingly recognised as a powerful tool to perform research (Kozinets 2002b; Langer and Beckman 2005). The striking feature of the process is that weblog/forum participants seem not to become passive recipients, but in contrast, their intention is participation and commitment.

\section{Context}

A hybrid car market seems to be the result of continuous push for technological innovation exercised by Toyota Motor Corporation. Honda, Ford, General Motors, and DaimlerChrysler start introducing their own versions of hybrid car brands. The hybrid technology is based on combining different sources of power to drive a car engine: electricity and petrol. A computer controls and calculates how much power from which source is needed in every single driving situation. Toyota emphasises the idea of sustainable mobility to promote its hybrids. They planned the launch of a US $\$ 60 \mathrm{~m}$ advertising campaign to convince car market members that Prius is the only robust automobile solution for the so-called sustainable mobility dilemma (The Economist 2005a). The sustainable mobility dilemma stands for a situation where there exists a conflict of interests between the increasing needs for mobility and the long-term environmental/social health of society. There are seven goals identified by the World Business Council for Sustainable Development to tackle the problem (Table 1). The sustainable mobility has been defined as "the ability to meet the needs of society to move freely, gain access, communicate, trade, and establish relationships without sacrificing other essential human/ecological values, today or in the future" (WBCSD 2004, 2).

TABLE 1

Sustainable Mobility Goals

Goal one: Reduce conventional emissions from transport so that they do not constitute a significant public health concern

anywhere in the world.

Goal two: Reduce GHG emissions from transport to sustainable levels.

Goal three: Reduce significantly the number of transport-related deaths and injuries worldwide.

Goal Four: Reduce transport-related noise.

Goal Five: Mitigate traffic congestion.

Goal Six: Narrow mobility divides that exist within all countries and between the richest and poorest countries.

Goal Seven: Improve mobility opportunities for the general populations in developed and developing societies.

\section{Research Procedure and Sources}

The qualitative data analysis software QSR NVivo 2.0 was used to organise and analyse the data. Open and axial coding has been performed to identify the categories and dimensions. This method itself may seem to be "reductionist", however, the reduction here is to wholeness, not to fractions. As the purpose was to describe the dynamic nature of systemic communications, only certain categories, in our view, could actually contend for centrality. The progressive centralisation (von Bertalanffy 1950) in systems happens in a dynamic and chaotic way. This process never develops stable structures, so our interpretation also follows this dynamism, thus matching 
the complexity of the system and avoiding artificial reductionism. The sources of the retrieved qualitative data for this study are the discussion, forum, and weblog sections of several websites. They are www.HybridCars.com, www.Priuschat.com, and www.GreenHybrid.com. The data set retrieved from these websites consists of highly unstructured and chaotic contributions of a large number of participants. As online nicknames are used for identification, it is highly improbable that contributors can be fully identified unless they tell about themselves. A concern might arise that these domains are likely to be "contaminated" by agents other than consumers. However, this was to be expected. Communication is not one-way message sending by a certain homogenised group, but a chaotic appreciative interaction of many involved. Our study should not be confused with factor-controlling experimentation based on pure samples. Understanding the problem of organisation calls for representation of the complex reality as it is. We see the marketing system as comprising all citisens regardless of their temporalised role-taking practices.

\section{Framework}

\section{FINDINGS}

The framework given in Figure 1 describes the process of autopoiesis in the self-referential system of citisens' experiences concerning one of the aspects of car driving such as fuel-efficiency. The order and structure of the framework should be taken as merely indicative and relative. The framework should be understood as a single snapshot of a dynamic system, a kind of a transient solution, which may go through nonlinear transformation, or even bifurcate (change abruptly) suddenly at any time to present itself using a different point of autopoietic observation.

FIGURE 1.

The Framework

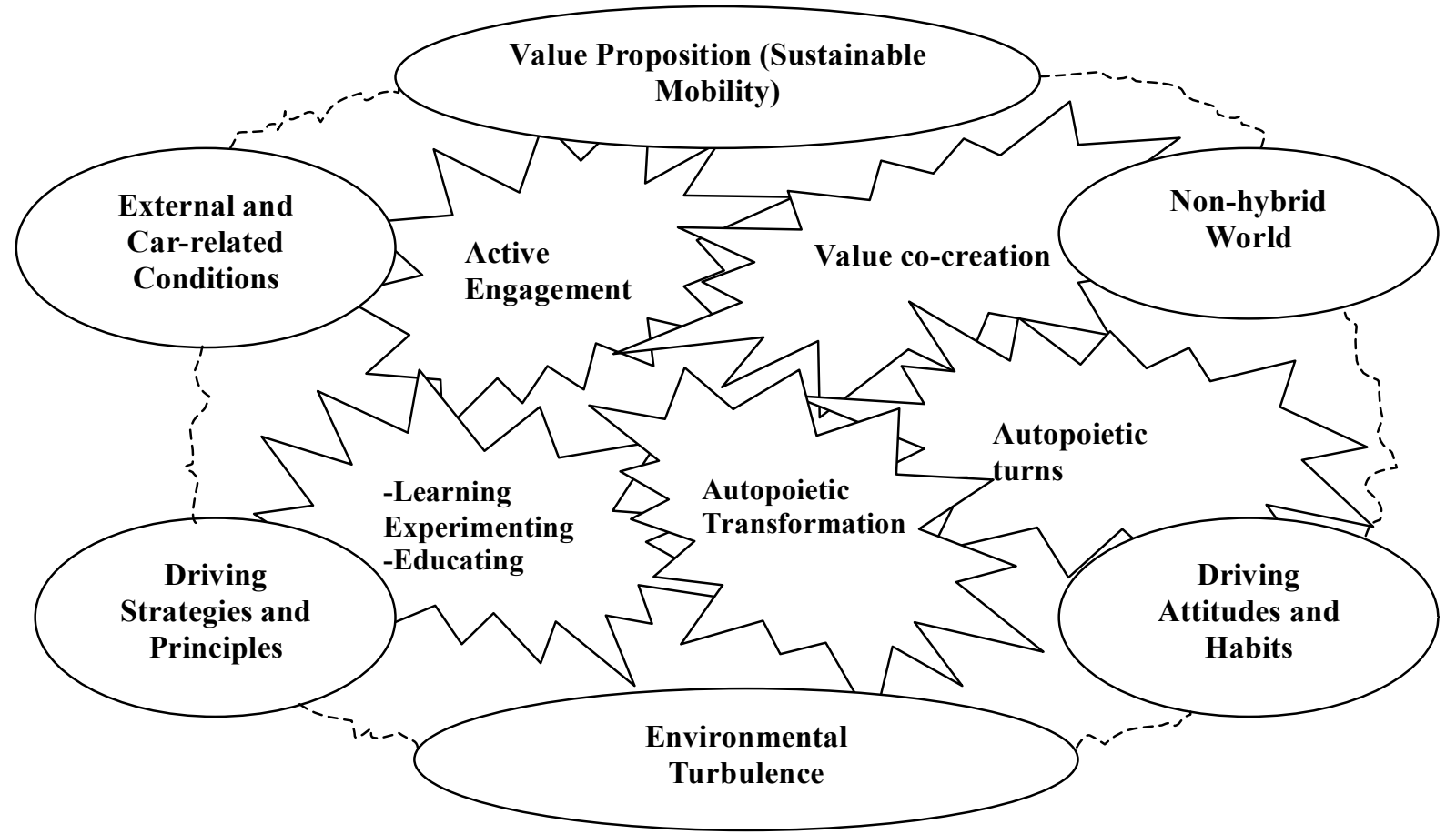

The framework illustrates the dynamic nature of the hybrid-car-marketing-system. The terms are provisionally divided into two broad groups of categories: process factors and boundary conditions. The process factors (stars), which exist in symbiotic relationship with the other group, are considered to be in the heart of the process. The boundary conditions (ovals) are not only the borders of the system, but also its inseparable components. The meanings of these categories are expected to unveil in the process of the discussion of the findings, so the omission of their definitions at this point is deliberate. They all in totality are thought to underlie the process of emergence of autopoietic turns in the marketing system. The process is dynamically settled and reproduced in the condition of continuous cycles of autopoiesis. The conditions (seemingly external effects and consequences) of systemic communications are recursively used as inherent parts of the system to reproduce similar communications. As the environment is characterised with a higher degree of complexity, uncertainty, and chaos, the overall autopoeitic turn 
selectively focuses on relevant issues (boundary conditions) and transforms them into the systemic mechanisms at the boundaries. The structure is generated by the unity of all elements within the system.

\section{Process of Autopoiesis: Major Concepts}

Value Proposition versus Value Co-creation. The category value proposition is reflected in the notions of the synergy drive, being in control, hope, potentiality, and 'piein-the-sky'. The common assumption is that all credit should go to the Toyota organisation for the development and fast expansion of the hybrid-car markets. However, under the theory of autopoiesis the company's actions are merely seen as an insignificant part of the total system of communications. A company is only able to make a value proposition (Vargo and Lusch 2004), which may get transformed in the cycles of autopoietic re-adaptation. In this case, the wholeness of value proposition (complexity related to sustainable mobility) has been narrowed down into promising users that they can take personal charge in saving fuel in a quite controllable manner, while minimally sacrificing driving comfort. This meaning is reflected in Toyota's concept of the synergy drive. The complexity related to the state-of-art technology, the future of the planet, the new alternative sources of energy, prominent environmental issues, sustainability, safe driving conditions, to name but a few, all have been reduced to a simple gauge, a computer calculator (being-in-control) that shows how many kilometres (miles) are driven per litre (gallon) of petrol burned:

"One of the biggest advantage[s] of ... a gas/electric hybrid is that they come standard with instantaneous mileage calc[ulator]. If all cars had this... more people would "learn" to drive to get better MPG. (Communication 1 (c1) - a representative fragment of a contribution by a participant in a weblog/forum discussion - the fragments hereafter will be marked as $c 2, c 3, c 4 \ldots$ and so forth).

The autopoietic process rendered this simplifying proposition a border for the system, a base for creation of internal complexity and a potential from which to tap an endless metamorphosis of communications. This proposition is invariantly linked to hope (Belk 1996) that being-in-control of petrol waste to some extent would deliver the much wanted public welfare and environmental balance (sustainable mobility):

The reason hybrid cars are flying off dealers' lots is not because they make such a galvanizing financial brief. It's because people of goodwill, conservative and liberal, are growing weary of the moral calculus of gasoline. What people are learning is that private choices have public consequences. (c2).

The reduced, narrowed-down value proposition is anything but an indicator of the promised potentiality for consumers which must be taken advantage of:

“...see what kind of mileage is possible with hybrids. The average (mean) is not indicative of what gas saving techniques can produce in a hybrid [car], it simply blows away a conventional car..." (c3).

The hope for endless potentiality serves as a starting point for the recursive turns of communications. It serves as a common platform, upon which co-creative experiences are built (Prahalad and Ramaswamy, 2004). However, citisens are wary and sure that the value proposition from a company is not a "magic bullet" for all the concerns, rather it is a "pie in the sky" (a concept, naturally found in the data, an in-vivo term), which must be actively sought by relevant actions. Owning a hybrid car is not seen as a guarantee of sustainability, but the way this value proposition is purposefully acted upon may have promised some hope.

The concept value co-creation is based on the following categories: unique fuel-efficiency experience, variability, inconsistent measuring, and power laws. The unique fuel-efficiency experience should not be taken as the extent of fuel spending expressed numerically as quantity, rather it represents the unity of all consumer experience related to the actions, which led to the level of fuel spending. Drastic variability in reporting fuel-efficiency indicates that its comprehension depends upon a myriad of factors ranging from conditions, actions, and expectations to the ways of defining, calculating, and measuring. The actual reported level of fuel-efficiency varied from as little as $19 \mathrm{mpg}$ (miles per gallon) to more than $100 \mathrm{mpg}$. Many accounts reported difficulties in measurement (inconsistent measuring):

"I would like to say one thing more about the bragging. I have watched the mpg calculator in my 2003 $\mathrm{HCH}$ and I know if I work that calculator just right I can make it say I get $70 \mathrm{mpg}$ and I really don't. I know exactly the points on the mileage of a trip where that calculator takes a reading of your mpg on the scale and averages that into what it already has. If I were really being careful and watching that I could get off the gas or coast at those points and make the calculator give me excellent readings. However, all of the mpg I have I calculate the oldest way known. Start with a full tank of gas drive the distance, record the distance, fill the tank back up with gas, record the gallons of gas you buy and then calculate. That is the only real way to know what your mileage is. If you are only looking at that calculator in your car you could be getting a lot different mileage that you think" (c4).

Moreover, the highly interactive, complex systems feature the characteristics of power laws (Marion 1999; The Economist 2005b). Similarly, power law probability distributions could be fitted to the reported fuel efficiency data, which could be explained in terms of highly dynamic interaction among the terms. In this case, the Pareto probability density functions would signify higher probability that a large number of situations be clustered around the manufacturer's advised level of the variable, whereas the probability (or fraction) of getting the higher levels of fuel efficiency would steadily decrease.

Autopoietic Transformation. Uncertainty with measurement appears to contribute to the alternative mode of value to that advocated by the marketer. In the system, the marketer's efficiency has turned into play, the quality has been taken as beauty (Holbrook 1994). The shift in the value transforms the "extrinsic" nature of the proposition (a means to self-oriented ends) to the "intrinsic" quality (an end in itself) (Holbrook 1994), its character changed from 
instrumental to ludic (playfulness), from practical to autotelic (action is a reward in itself rather than being associated with some outcomes), from utilitarian to personal appreciation (Holbrook 1999). This process we call the autopoietic transformation of value. The categories retrieved from the data that support the idea are obsession, playful behavior, and artful driving:

What extremes? For example this summer has been very hot. Mid 90's, 99\% humid. Sticky. While almost everyone just runs their AC I have not. Many times I've brought along a 6-pack sise cooler with icewater and a dabbing cloth... (c5). / I'm a mileage freak... (c6). / My favorite gear is neutral. Every chance I get, I run with the engine off and the ignition switch on. My kids call it driving "Soap Box Derby" style. They are all Soap Box Derby racers. We own three All-American soap box derby cars, and I am a race official. We have been doing this for five years. So you can see, coasting downhill has become a family hobby $(c 7)$. / Finding the best balance between using the battery for auxiliary power (when getting up to speed) and using the gas engine only when cruising may turn out to be an art $(c 8)$.

It became increasingly clear that hybrid car consumption is not about saving costs. A big part of discussions were about why hybrids should not be considered as a means of a return on investment. Small savings in operating costs are not able to off-set a huge premium paid for acquisition of this type of technology visà-vis comparable models. A company would urge users to note the proposition of a clear advantage in fuel economy, thus emphasising a "hedonic" character of value (Podolny and Hill-Popper 2004), that is reducing value to a set of measurable criteria. However, experiences communicated within the system indicate that it rather fits a "transcendent conception of value" (Podolny and Hill-Popper 2004), which stands for a holistic blend of mutual appreciation through reduction of a social distance between the object and the subject.

Autopoietic Turns. The autopoiesis is based on selfreferential differentiation (Luhmann 1995). The categories in the data that indicate to this phenomenon are selfdifferentiation ((in)efficient driving, identity, and legitimacy), the autopoietic closure and (the initiation of) change. A segmentation (value) strategy is directed towards creating a difference along industrial product-categorical delineation, such as between hybrid car(brand)s and nonhybrids. However, the observation shows that the selfdifferentiation in the system does not match this assumption; rather differentiation occurs in the level of communications. The difference is not constructed along the industrial categorisation of models; instead, it is built up on the difference between efficient and inefficient driving styles. As a means to differentiation and status expression, forum interactors usually start up with presenting their identity, which contains information on an average level of attained mpg $(\mathrm{km} / \mathrm{l})$, a number of hybrid-experience years, and a distance driven in a hybrid-car. This kind of informational density itself conveys a feeling of the high complexity of driving experiences. Most interactors whose intention is to give advice to others try to attach high legitimacy to their expertise by expressing their identity in this way. Also, self-differentiation may happen in stages of self-contentment. The self-contentment occurs when one is satisfied with the level of one's own achievement, and acts toward to the very self-chosen result. Many refer to guys in $40 \mathrm{~s}, 50 \mathrm{~s}$, and so forth, which indicate to the level of contentment with the unity of actions to achieve the certain level of mileage. This way of "driving to the result" points to the existence of the autopoietic closure:

Your commute is what you make it. I don't expect you to understand that $(c 9)$.

Autopoietic Closure and Environment. The extent the actors differentiate and distance themselves from the nonhybrid world is the defining characteristic of the closure. This would determine how open or closed the system becomes in its evolving self-referentiality. The closure actually plays the role of a strategy in dealing with increasing environmental turbulence, characterised by the external and internal complexity. Although not all the turbulence is related to the dynamics of the system, its understanding (meaning) is co-created within the system. The closure filters the complexity and creates a temporal internal order which may develop into the internal complexity. The internal complexity increases by creation of changes in driving attitudes and driving habits. As soon as the driving attitude changes, actions pass the systemic borders and emerge in a qualitatively different context:

The fact that hybrid ownership bridges traditional political, cultural, and philosophical barriers is a major plus. It shouldn't require knowing the secret "with it" club handshake to be welcomed to the hybrid community (c10).

Active Engagement. The self-legitimising recursivity emerges when consumers interactively introduce (co-create) certain driving strategies and principles, and then actively implement them and use them as justification. This kind of activity normalisation is actually done through differentiation, as certain relevant strategies are usually chosen among many available in the perceived "horizon of driving strategies". The examples for the system-unique driving strategies to emphasise here are pulse-and-glide, and drafting. The pulse-and-glide technique is the most complicated strategy in which one tries to maintain speed and when necessary to accelerate by only using electric power while the petrol engine is in hold. Drafting means getting in close behind big trucks on the highway to get advantage from the aerodynamic corridor created by them. Additionally, within the system, everyone gets affected with certain self-differentiating driving principles such as minimum braking, smooth start and acceleration, keeping momentum of speed, slow driving, and so forth. Such "insystem-principles" have predominantly been understood as having positive connotations vis-à-vis rival principles The hybrid driver is the proud implementer (enjoins "good" and prohibits "wrong") of the systemic strategies and principles. The factor that gives this experience the recursive dynamic is the active interaction with the external and car-related conditions. The external conditions can be divided into weather factors (air temperature, humidity, whether it is raining or not, seasons) and geographic factors (local topography, road conditions, traffic, route, and driving time). The car-related conditions are ventilation, vehicle weight, speed, aerodynamics, tire condition, and petrol quality. This list is not exhaustive. The permutation of the 
factors would emerge in a driver's experience in quite a chaotic way, yet a user is not a passive acceptor, rather he/she is an active interactor, even a constructor of his/her experience. The type and character of active engagement and experience construction largely depends on the intentional foci of actions. Even such uncontrollable factors as outside temperature can pro-actively be interacted through the intentional action:

"...it sounds well deep, like walking on the rice paper and not leaving a mark like David Carradine in Kung Fu. Aside from accel work, this guy covers almost all of the front grill and half the engine room in winter, has extended the air intake pipe, and uses the equivalent of a block heater on the engine. It sounds like he is using a halogen room heater, a somewhat improvised solution" (c13).

The re-production of the conditions-consequences cycle would not be possible without continuous learning, educating and experimenting within the system. Interestingly what emerged is that any one of these three may appear as a necessary precondition for the others, or/and take turns in preceding each other. They emerge in a concerted unity.

\section{Meanings/Value Drift}

The marketers are diligently uttering the sustainable mobility values. Here we deliberately avoided using the term "communicating". The communication is complete (becomes a unified system of meanings/value) if there is understanding (appreciation) in the 'reader'. The drift in the originally proposed value may have developed due to the unified interaction between the process factors and the boundary conditions, which may have bifurcated through the autopoiesis. We would like to discuss three points related to the sustainable mobility issue in the context of this particular system: harmful emissions, safety, and widespread mass access. A benefit the hybrid technology offers is drastic reduction in carbon dioxide emissions levels per a car. However, how this benefit might relate to the total emissions produced within the system is, as yet, uncertain. Extensive proliferation (and ludic experimentation) of the technology may have resulted in the higher rates of demand and usage. For example, Toyota acknowledges failure in reducing total emissions in absolute terms (Toyota Motor Corporation 2005). However, could such a complex term as sustainability be reduced to a certain measurable foundation (here, it is fuel-efficiency and emission reduction)? As far as systems thinking is concerned, probably not. As soon as we (citisens) are proposed a certain measure, we autopoietically render it to the transcendent value. We play with it, marvel at it, get obsessed, and experiment with it. Thus the system thrives. Moreover, much debate online was on the relative fast wearout of the hybrid system components, which would mean faster accumulation of waste in global terms. Yet the biggest issue that must be noted is the safety of the users. Could we imagine how dangerous the traffic might get if some of drivers would unexpectedly start drafting or pulseand-gliding? This turn could become a self-defeating strategy for companies who would like to argue that hybrids are about sustainability. The final concern is about enabling access for the global population to the beneficial technology. In terms of costs, the hybrid models are still inaccessible to most drivers in the developed world, not to mention the developing regions. One might wonder if it is not becoming an entertainment of a prosperous few that is covered in the "sustainability cloak of innocence".

\section{DISCUSSION}

It seems that hybrid-car acquirement does not become an automatic guarantee of sustainability as claimed by producers. To be sustainable what might really matter is the way and attitude by which the value proposition is acted or communicated upon. Manufacturers' communications are but a small part of the whole marketing system. The interactivity appears to be out of the control of any agent. Luhmann (1995) speaks of a "double contingency" in this regard (i.e. two agents depend on each other to create their respective self-identities), however, we see it as a multiple contingency. System boundaries are far from being material or tangible, they are communicative, and they tend to become actualised through considerable changes in actions (communications). For instance, "border-crossing" happens when a user starts driving in a "hybrid way", which is "constructed" to be totally different to the conventional way of car driving. The difference among consumers is traditionally understood in terms of demographic, psychological, or geographic factors. In contrast, our theory emphasises the case of the dynamic communicative differentiation that is based on a totality of actions (interactions). So borders may not be there to set apart intra-system and inter-system relationships, but serve as a "filter" that helps to reduce the environmental complexity into a manageable intra-system autopoiesis. The wholeness co-created must be meaningful in terms of the current practicality (Luhmann 1995). However, sustainability is complex and uncertain, so no particular system can "digest" it within its reductionist circularity of meaning. Nevertheless, it may have a chance to be actualised in the intersection of several systems. For citisens to reach "sustainability emancipation", the transcendence over the narrow autopoietic turn is required.

\section{CONCLUSION}

It has been suggested that consumers create autopoietic turns in using value propositions and meanings, and the process is not always as it is intended by producers The value assumes a totally different meaning through cocreative experiences triggered by self-referential communications. In the context of the autopoiesis, communications selectively create certain relevant conditions, and these conditions are in turn used to create similar communications. The communications are directed toward creating only those conditions which would enable the regeneration of the same kind of communications. By creating a full dynamic cycle the marketing system closes itself apart from the environment, especially its uncertain complexity, and then starts adapting to its own complexity. The excess self-adaptation might lead to an ever-increasing chasm between the original value and the transformed value. The system, particularly its active part, which is reflected in the participant's communications, is driven by its own autopoietic (regeneration) motives, rather than the sustainability of the environment. As communications are temporal, the sustainable self-emergence prevails regardless 
that the value of environmental sustainability is being continuously infused into the systemic operation. It seems natural, because the environment is cyclically constructed in each autopoietic turn by the same system for its own purposes. The ideal of sustainability, as the dominant rhetoric, is made to serve sustainability, but in this case it is that of the systemic autopoiesis. The question remains open: Is this process itself sustainable?

\section{REFERENCES}

Alderson, W. (1965), Dynamic Marketing Behavior: A Functionalist Theory of Marketing, Homewood, Ill: Irwin.

Bartels, R. (1970), Marketing Theory and Metatheory, Homewood, Ill: Irwin.

Belk, R. W. (1996), "On Aura, Illusion, Escape, and Hope in Apocalyptic Consumption: The Apotheosis of Las Vegas," in Marketing Apocalypse: Eschatology, Escapology and the Illusion of the End, ed. Stephen Brown, Jim Bell and David Carson, London: Routledge, 87-107.

Catterall, M., P. Maclaran, and L. Stevens (1996), "The Pathetic Phallusies of St. Thomas Aquinas and Why Marketing Should Give Eve a Break," in Marketing Apocalypse: Eschatology, Escapology and the Illusion of the End, ed. Stephen Brown and Jim Bell and David Carson, London: Routledge, 223-36.

Dixon, D. F. and I. F. Wilkinson (1982), The Marketing System, Melbourne: Longman Cheshire.

Dowling, G. R. (1983), "The Application of General Systems Theory to an Analysis of Marketing Systems," Journal of Macromarketing, 3 (2), 22-32.

Firat, F. A. and A. Venkatesh (1995), "Liberatory Postmodernism and the Reenchantment of Consumption," Journal of Consumer Research, 22 (3), 239-67.

Fisk, G. (1981), "An Invitation to Participate in Affairs of the Journal of Macromarketing," Journal of Macromarketing, 1 (1), 3-6.

(1967), Marketing Systems: an Introductory Analysis, NY: Harper \& Row.

Holbrook, M. B. Ed. (1999), Consumer Value: a Framework for Analysis and Research, London; NY: Routledge.

(1994), "The Nature of Customer Value," in Service Quality: New Directions in Theory and Practice, ed. Roland Rust and Richard Oliver, Newbury Park, CA: Sage, 21-71.

Holstein J. A. and J. F. Gubrium (2005), "Interpretive Practice and Social Action”, in The Sage Handbook of Qualitative Research, ed. Denzin K. Norman and Yvonna S. Lincoln, Thousand Oaks: Sage, 483-505

Holt, D. B. (2002), "Why Do Brands Cause Trouble? A Dialectical Theory of Consumer Culture and Branding," Journal of Consumer Research, 29 (1), 70-90.

Kozinets, V. R. (2002a), "Can Consumers Escape the Market? Emancipatory Illuminations from Burning Man," Journal of Consumer Research, 29 (1), 20-38. (2002b), "The Field Behind the Screen: Using Netnography for Marketing Research in Online Communities," Journal of Marketing Research, XXXIX (February ), 61-72.
Kuhn, A. (1963), The Study of Society: A Unified Approach. Homewood, Ill: Irwin.

Langer, R. and S. C. Beckman (2005), "Sensitive Research Topics: Netnography Revisited," Qualitative Market Research: An International Journal, 8 (2), 189-203

Lazer, W. (1971), Marketing Management: A Systems Perspective. New York: Wiley.

Luhmann, N. (1995), Social Systems, Stanford, CA: Stanford.

Marion, R. (1999), The Edge of Organisation: Chaos and Complexity Theories of Formal Social Systems, Thousand Oaks, CA: Sage.

Maturana, H. R. (1981), "Autopoiesis," in Autopoiesis: A Theory of Living Organisation, ed. Milan Zeleny, New York: North Holland, 21-33.

Podolny, J. M. and M. Hill-Popper (2004), "Hedonic and Transcendent Conceptions of Value," Industrial and Corporate Change, 13 (1), 91-116.

Prahalad, C. K. and V. Ramaswamy (2004), "Co-creation Experiences: The Next Practice in Value Creation," Journal of Interactive Marketing, 18(3), 5-14.

Reidenbach, E. R. and T. A. Oliva (1981), "General Living Systems Theory and Marketing: A Framework for Analysis," Journal of Marketing, 45 (4), 30-37.

Sheth, J. N., D. M. Gardner, and D. E. Garrett (1988), Marketing Theory: Evolution and Evaluation, New York: Wiley.

Shultz II, C. J. and M. B. Holbrook (1999), "Marketing and the Tragedy of the Commons: A Synthesis, Commentary, and Analysis for Action," Journal of Public Policy \& Marketing, 18 (2), 218-30.

The Economist (2005a), "Battery assault," The Economist, $376(8445), 65$.

(2005b), "Rules of Engagement," The Economist, 376 (8436), 74-75.

Toyota Motor Corporation (2005), Environmental and Social report 2005. Toyota City, TMC: Environmental Affairs Division.

Varey, R. J. (2000), “A Critical Review of Conceptions of Communication Evident in Publications of Business and Management," Journal of Communication Management, 4 (4), 328-40

(2002), Marketing Communication: Principles and Practice, London: Routledge.

Vargo, S. L. and R. F. Lusch (2004), "Evolving to a New Dominant Logic for Marketing," Journal of Marketing, 68 (1), 1-17.

Von Bertalanffy, L. (1950), "An Outline of General System Theory," British Journal for the Philosophy of Science, 1 (2), 134-65.

WBCSD (2004), Mobility 2030: Meeting the Challenges to Sustainability. Geneva: WBCSD.

Yadav and Varadarajan (2005), "Interactivity in the Electronic Marketplace: An Exposition of the Concept and Implications for Research," Journal of the Academy of Marketing Science, 33 (4), 585-603 